\title{
Evolution of Fan Culture Under the Influence of Audience Labour in Context of Attention Economy
}

\author{
Yuting Liu ${ }^{1, a, \dagger, *}$, Xinyun Luo ${ }^{2, b, \dagger, *}$, Wentao Yan ${ }^{3, c, \dagger, *}$ \\ ${ }^{1}$ Liberal Arts, Culture and Society, King's College London, WC2R 2LS, United Kingdom. \\ ${ }^{2}$ Faculty of Arts and Social Sciences, The University of Sydney, Sydney, NSW 2006 Australia. \\ ${ }^{3}$ School of Arts and Cultures, Newcastle University, NE1 7RU, Newcastle, United Kingdom. \\ These authors contributed equally. \\ ${ }^{*}$ Corresponding author.Email: ${ }^{a}$ k21129155@kcl.ac.uk, ${ }^{b} x l u o 2685 @ u n i . s y d n e y . e d u . a u,{ }^{c} w . y a n 5 @ n c l . a c . u k$
}

\begin{abstract}
Changes in multimedia technology and production have instead made fandom a major form of consuming in the previous few decades and fans are considered as an excessively obsessive subset of the audience. An abundance of burgeoning shows in China's entertainment industry have emerged in an endless stream in the latest decade. The survival show has become the mainstream reality show and increasingly sought after by fans. Audiences are able to use financial support and other ways to fully engage in the show and lead the success of the debut of their idols. This phenomenon is becoming fanatical. Due to this type of interactive participation mode, a series of male/female group survival shows, for instance Youth with You and Chuang, have made considerable profits for Chinese entertainment industry. Nonetheless, some abnormal and unhealthy phenomena occurred in fandom due to the lack of regulation in fan culture. The sensual labour in today's fan economy are being digitized and used as unpaid labour in form of exploitation by the capital. This paper traces the historical development and current situation of both fan economy and fan culture, looking particularly at the factors and impacts of a series of abnormal and unhealthy phenomenon that have occurred in today' s Chinese fandom, to allow for a discussion of the relationship between fans and idols by using the concept of 'audience labour' as the theoretical framework. In addition, some suggestions will be put forward for the future approaches of the government and the public regulating and normalizing fandom in terms of the development trend of fan culture.
\end{abstract}

Keywords: Fan Culture, Audience Labour, Fan Economy, Attention Economy.

\section{INTRODUCTION}

Nowadays, there has been an ever-growing trend of fan culture in modern Chinese society, especially among Chinese gen-zers. The boom of Chinese fan economy has been triggered, with numerous reality shows, celebrity endorsement deals, and the expanding entertainment market in Chinese society. For the recent years, the idol reality shows to create and promote boy groups and girl groups after a survival competition has gained huge momentum. In those shows, "trainees" from different entertainment companies are trained in dancing, singing and acting would be voted by the public audience through on-line platforms. The trainees with the highest votes will participate the final line-up of the boy group or girl group. For instance, Produce 101 China in 2018 attracted more than 4.3 billion views on Tencent Video and fans generated over 20 and 40 million RMB, for "Idol producer" (iQiyi) and "Produce 101 China" respectively [1]. Entertainment and media companies could also rake in huge amount of money via their VIP memberships, event tickets, and endorsement deals. In a nutshell, the fan culture and fan economy in China has been deeply interrelated.

With the rapid revolution of network technology in the past two decades, the development of the world's entertainment industry has also become extremely prosperous. Many beloved films continue to appear in the Hollywood, and the star-making assembly lines in South Korea are even more enduring, however, what is more worthy of attention is that variety shows in China's entertainment industry have begun to transform into idol-cultivating types in recent years. Audiences can use financial support and other tools to participate in and 
influence the success of the debut of the idols in the show. Many fans of idols have appeared organised and structured to provide financial support for the idols they fond of, which this phenomenon is becoming fanatical [2]. Because of this interactive participation mode, a series of variety shows, such as Youth with You and Produce 101, have made considerable profit returns for investors and become a new territory with significant research value. Many scholars have studied the existing capital operation logic, the participatory culture formed by the program itself, and the construction of fans' discourse power [2, 3, 4]. However, through reviewing previous studies, it can be suggested that there are few studies on how to develop the fan culture of Chinese entertainment industry in the future and how to constrain and normalise it.

The aim of this research paper is to investigate and research on the development of fan culture in Chinese entertainment industry in recent decades so as to reflect upon several abnormal and unhealthy phenomenon that have occurred in today' $s$ Chinese fandom, as well as the negative effects and consequences brought by these phenomena. Furthermore, this research will give a speculation on the future trend of fan culture in Chinese entertainment industry and propose a set of suggestions and approaches on how the Chinese government and the public could regulate and normalize fandom in terms of nowadays fan culture.

In order to achieve the aim of this study, the historical development and current situation of both fan economy and fan culture will be discussed in the first part of the paper. Secondly, this study will put focus on the factors and impacts of a series of abnormal and unhealthy phenomenon that have occurred in today' $\mathrm{s}$ Chinese fandom by investigating the adverse event of irrational fans of idols in talent shows purchasing a large number of milk products and intentionally dump them just for voting for their idols so as to conduct a qualitative case study. In addition, this paper will give a deep review and discussion on the relationship between fans and idols by using the concept of 'audience labour' as the theoretical framework. Finally, some suggestions will be put forward for the future approaches of the government and the public regulating and normalizing fandom in terms of the fan culture' $s$ development.

\section{FAN CULTURE AND FAN ECONOMY}

The shifting nature of connection and relationship between celebrities and fans have been witnessed. With the development of social media platforms, fans, who acted as only passive recipients in the past, are now turning into an important role in the media and entertainment industry, generating their original fan works like fan art, fan videos and fan fictions. In the pre-internet era, the interaction and communication between fans and artists, fans and fans are hindered in various ways, due to the limited communicating means. The emergence of digital networks creates a new context for the whole industry. Shuojia Guo points that, the rise of social media platforms has greatly broadened the scale of fan groups. Because the fans can communicate and discuss on social media in real time, which all result in the prosperity of the immediacy and participation of the current fan culture [5]. Meanwhile, China's media and entertainment companies have already tried to embrace the creative powers created by fans so as to seek new ways to develop, invest in, and nurture their fan community.

In the second decade of the 21 st century, a new boom of fan culture can be seen in China due to the persistently changing and upgrading social media platforms, which has increased people' $\mathrm{s}$ stickiness and activity form an excellent environment for fan culture to develop and prosper. Weibo, China's largest entertainment social media platform could be taken as an example. When an user follows or thumbs up a celebrity, he or she will be immediately notified of this celebrity's tag, channel, and fan group. Meanwhile, the user will be frequently feed the notifications and ads related to or similar to this celebrity.

Moreover, celebrities and agencies have also deployed social media to enhance the sense of intimacy promote interaction with fans and fan groups to generate more profits, which means fans are not the only ones who are discovering the power of social media. Celebrities and the business communities and agencies behind them are also using the values generated by the social media platforms. Take the sudden emergence of pop boy group Nine Percent, which was promoted by the iQIYi reality idol produce program, and Rocket Girls from Tencent Video' s similar show Produce 101 [6]. Fans contributed over 20 and 40 million RMB, respectively, which has proved their enormous economic power and influence. In the process of them,some certain online fan clubs with high efficiency played an important role. Some of which even have company-like structures encompassing some essential departments such as Core Management, Design, Copy writing, Data, Comment Control, and Front line. In the Chinese version of GQ, an idol photographer states that there are enormous people like her out there, referred as

"Site Sisters" [6]. According to the author in GQ' s article, between summer 2016 and summer 2018, 20,000 photos of 15 artists were took over by her and posted 1,5000 photo-shopped versions of them on different social media platforms [6]. According to the data, Successful Site Sisters could even earn 15,000RMB (over 2,000USD) in a week by selling photos and peripheral products of their idols to other fans and fan groups [6]. 
This boom of fan productions and fan works have been witnessed to the public including fan fiction, fan videos, fan letters. According to Jenkins, the reason why more and more people are participating in this creation is because the network provides them with a safe place where they can experiment with new passions or activities [7]. Through social media platforms and upgrading technologies, every single fan can always find a way to take part on the whole process of entertainment industry and attain a sense of belonging and satisfaction. Many fans with specialties in certain fields even will give instructions and help to rookies how to better promote their idols and how to interact with them.

To sum up, in the process of fan culture and fan economy, the exchange of traditional media to social media promotes the development of the participatory culture of fandom, which has shifted them from the receiver to the producer. Meanwhile, the fan culture and fan economy are tightly connected. The increasing fan culture contribute the economic power of fans and fan groups in the entertainment industry, meanwhile, the created fan products boost the scale of fan culture.

\section{FAN CULTURE AND ITS INFLUENCE}

The history and evolution of fan economy was reviewed in the previous chapter, while fan culture and its research will be summarised in the following chapters.

Fan culture, also called "Fandom", it has a very long history. Fans of the detective character Sherlock Holmes in literary fiction were widely regarded as the first modern fan group to appear, and they even hold a public parade for Holmes' death [8]. Second, the word was first used in 1903, not just emerge in the web 2.0 era. According to the book published by Cornel Sandvoss in 2005, he defined fandom as: "the regular, emotionally involved consumption of a given popular narrative or text" $[9,10]$. A simpler explanation refers to the subcultural group of fans who share common interests and hobbies for a certain object or topic. This object or topic can be a large number of different contents, such as TV series and movies, cartoons, popular magazines, video games $[11,12,13,14]$. Before the popularization of digital media, members of the fandom will organise their own theme activities, exchange their opinions or critics, and share the unique resources they have obtained. In the media field, the opinions of fan groups can even affect the media itself. For example, after the show Firefly was cancelled, the discussion among its fans succeeded in attracting the attention of the production company, and the screenwriters and production company continued to film a movie about the show Firefly [15]. It can be considered that fan culture is very influential. However, in the digital era of rapid development of social media, the construction of fandom in social media and its influence have become a field worthy of attention and research.

First of all, the emergence of social media has strengthened cultural exchanges between individuals and groups, while allowing fan groups to make more direct contributions to their idols or society. A study on the fan groups of ARMY BTS Indonesia in the LINE Webtoon app showed that fans will use LINE Webtoon to upload digital comics that they describe in order to participate in dedication to idols [16]. The study suggested that the higher the degree of participation of fan groups in online and offline activities, the more they can strengthen the existence of celebrity phenomenon, and help celebrities influence the mass media [16]. In addition, the fan groups also provide some new business opportunities for other related industries. For instance, the research put forward that the fan group will use any ways or tools provided by the media to express their affection to the idol. Finally, some fan groups even spontaneously organise and participate in charitable events, which have a positive influence on society. For instance, fans of the YouTube video vlog channel “ Vlogbrothers" spontaneously founded an online community which called "Nerdfighters", they were committed to "decreasing world suck" [17].

However, the influence of fan culture is not all positive. Some negative and criticised phenomena have also appeared in society with the popularity of fan culture.

The reason for this phenomenon is that there are also different types of classes in the fan community spawned by fan culture. For instance, in a 2011 National Gang Intelligence Centre report, there are violent and nonviolent groups in Juggalo's fan subculture. Violent groups despise the non-violent and non-criminal Juggalo group, and even attack them [18]. Second, another study on K-POP fan culture in Singapore also found that a type of abnormal K-POP fans named "Sasaengpaen" would stalk idols and violate privacy. They would Use a variety of methods to approach idols to show their fanatical love, including using social media to build their own illegitimate groups and communicate with each other to achieve the purpose of stalking idols [19]. This phenomenon has been strongly condemned by the public, and even warned by the idols themselves. Hence, it can be considered that the popularity of fan culture in social media has also brought some undesirable effects.

\section{AUDIENCE LABOUR IN CONTEXT OF ATTENTION ECONOMY}

In pace with the rapid globalized development of media and entertainment industry in the recent decades, a large number of media production companies are seeking for new strategies to catch the attention of their 
audiences to the greatest extent as newly sprouted things emerge in an endless stream. In this context, "a new attention to attention is emergent" and the notion of attention economy is gradually taking a significant place in nowadays media culture, especially in the entertainment industry [20].

The traditional understanding of the attention economy, according to Simon, viewed attention as a type of commodity that could be traded in the media market and thus governed by the supply and demand laws [21]. This concept explains the increasing importance of audience attention in today' s society of post-industrial production [21]. The attention of audiences is considered as a "scarce and valuable commodity" in nowadays society where information and data play dominant roles in the the process of capitalization [21]. Therefore, the attention of audience could also be seen as a new form of labour in entertainment economy.

In context of the growing attention economy nowadays, "human attention is productive of value" [20]. With the growing informatization of the commodity production processes, the value of human attention, as a scarce and special kind of commodity, is determined by the abundance and coverage of information [20]. Thus, the capitalists have started to develop and formulate multiple strategies in order to capture audience attention for profit making. The rise of attention economy, as well as the globalized development of entertainment industry have revealed the reality that the commodity being traded in the entertainment market is productive labour itself in the capitalist media industry today [20].

We have stepped into an era marked by the economics' full incorporation of human senses. Audience attention is a new form of value-producing labour that represents the industrialization of human senses. The senses of audiences are collected and organized by mechanized networked media today as people are contributing their attention on a variety of social media sites [20]. For instance, the crazy confession of fans towards their idols posted on their social media accounts show the popularity of their idols. These fans also purchase everything their idols endorsed or even something they have used, which represents the commercial value of their idols. With all these economic data provided by their fans and audiences, they are able to make more profits. Thus, the capitalist firms would use this phenomenon to make profits. The attention of fans and audiences are producing values in entertainment economy and all the values are contributed without any rewards. It is essential to replace the conception of "attention as labour" with that of "attention as a special commodity" so as to understand the relation between productive value and sensual labour in the attention economy [20]. The labour theory of Marx is a valid framework to understand this idea.

Labour power is defined by Marx as "labour capacity" in Capital, which indicates that the capability of human beings to conduct a task that could produce use values is referred to as labour power [21]. To understand Marx's theory of labour power by considering the process of labour as the " materialization of labour power" , we could see that the capabilities are actualized as " value-producing activities” [21]. As what is discussed above, humans' sensual activities of watching, listening and reading activities of consumption could be treated as a special form of value-producing labour in the sense of the consumption [20, 23].

The journal Watching as Working: The Valorisation of Audience Consciousness by Sut Jhally and Bill Livant well explains the concept of sensual labour of audiences [22].

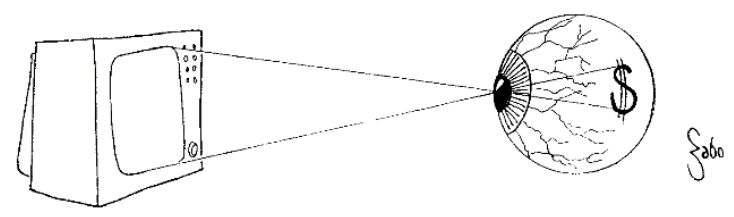

Figure 1. Watching as Working, Journal of Communication [22]

The Figure presented above demonstrates Jhally and Livant's argument that the audience senses is the commodity generated and exchanged by the entertainment industry rather than the medium under the conceptual framework of Marx [22]. The case of irrational fans of idols in talent shows purchasing a large number of milk products and intentionally dump them just for voting for their idols could be understood in this theoretical framework. Instead of actually selling media content to audiences, entertainment industry makes profits by selling audience attention to their ad suppliers [21]. This is how the labour process of sensual labour is formed. Through this special commodity exchange, capitalist media are able to control the human sensual labour process of signification and obtain the value from this process [23]. The Youth with you 3 program group exploited the audience attention by establishing the competition mode of voting for their ideal idols by scanning the QR codes in the bottle caps of the sponsored milk products. In order to support their idols, the audiences irrationally bought a large number of milk products, however, they were not able to drink them all. As the result of this, they had to dump all the milk. Although the behaviour was extremely wasteful, the program group and the brand benefited a lot from this. In this regard, audience labour has the capacity to produce 'surplus value' and the capital could 
therefore exploit and alienate it [21]. The labour is produced by audience on their own and purchased free of expense by the capital through the media content they initially consume. In term of this, there is validity to say that audience labour has become a type of capitalist exploitation. In the context of attention economy, audiences themselves are becoming the medium content in capitalist entertainment industry.

Beller states that "in the world of paying attention, humanity has become its own ghost" , which indicates that audience attention is gradually losing connection with our own experiences but "subsumed for capitalist production" instead [20, p.7]. The cognitive capacities of human beings, which is the sensual labour in today' s fan economy are being digitized and used as unpaid labour in form of exploitation by the capital [20].

\section{CONCLUSION}

The purpose of this article is to review the history and development of fan culture and fan economy and try to identify how it has become an extremely significant part of the entertainment industry. The structure of this paper is divided into three parts. First of all, the shifts in the relationship between fans and celebrities or stars in social media were reviewed. Secondly, the concept of fan culture and its history, as well as its evolution in the era of digital media were summarised in the second part. The influence of fan culture on society and celebrities themselves were also reviewed in this section. Finally, the theory of attention economy proposed by Johnathan Beller was used as a theoretical framework to discuss the economic operation logic of fan groups in the entertainment industry and explained how they become the significant part of the entertainment industry.

In the first part, the conclusion was drawn from the review that the form of connection and relationship between celebrities and fans has changed in the rapid development of social media. In the past, fan groups were just passive receivers of the messages sent by celebrities or idols. At present, fans have the power to participate in the development of celebrities and the entertainment industry. In the second part, the definition of Fandom and its history and development were reviewed. The findings of this part of the review were that fan culture could not only promote the influence of idols' media roles, but also become a group that produces positive contributions to society. However, it is worth considering that fan culture also has certain negative effects on society. Some fans with bad media characters will have a negative impact on idols and the society, even cause some illegal or violent incidents. Finally, the terms "attention economy" and "audience labour" proposed by Johnathan Beller were used in the review. The findings of this review were that fans' cognitive abilities as human beings, their sensory labour in the fan economy, were being digitised in the Web 2.0 era and were becoming an important part of the entertainment industry in the form of capital exploitation.

Chinese fan economy has proved that it encompasses much more than just a simple business relationship, instead, a complex culture which can reveal beliefs, customs and behaviours, which now has formed an booming industry. As the fan culture and fan economy is gaining momentum in China, fans are playing a more and more important part in entertainment industry and even society. In this case, agencies should take them into account when generating their marketing strategies or promoting their products. Meanwhile, the governments should enact laws and regulations on certain entertainment industry sectors to fill some legal and regulatory gaps. Since fans are actively engaging in fan production, some excellent content producers which make profits by their creations could probably lead to the controversy of the legitimacy as it violates the original producer' $\mathrm{s}$ copyright or intellectual property right. Also, the legal status of some fan productions stays unclear, which calls for more concern and effort. More importantly, being empowered in the whole industry, the operators and managers in the media and entertainment industry, the platform of fan culture and fan economy, should always keep professional ethics and social responsibility, instead of taking fans as the tool to rake in money.

\section{REFERENCES}

[1] Daxueconsulting. China's idol economy: how the Chinese fan culture is shaping entertainment and marketing,2021. Available at: https://daxueconsulting.com/china-idol-economy/

[2] Wang, W. Cultural Perspective of "Fandom Circle" and Ecological Reconstruction of Variety Show Entertainment Content. CHINA TELEVISION. 2021. p.67-70. doi:CNKI:SUN:ZGDD.0.2021-07014.

[3] Yan, H. Y. The capital logic in the operation of fan economy. Research of radio and television. 2021. p.43-46. doi:CNKI:SUN:SHGB.0.2021-03-015.

[4] He, A. A. Analysis of the Spectacular Phenomenon Based on the Theory of Media Spectacle_-A Case study of "Super Girl" and "Youth with You 2. Media Forum. 2021. p.53-55. doi:CNKI:SUN:CMLT.0.2021-14-026.

[5] Guo, S. Charging Fandom in the Digital Age: The Rise of Social Media, in: C. Wang (Eds.), Exploring the Rise of Fandom in Contemporary Consumer Culture, IGI Global, Hershey, 2018, pp. 147-162. DOI: https://doi.org/10.4018/978-1-52253220-0 
[6] Fan. S. Idol Hands:How China's Super Fan Groups Make and Break Stars Via the Multi-Million Dollar "Fan Economy", 2019, DOI: https://radiichina.com/idol-hands-how-chinassuper-fan-groups-make-and-break-stars-

[7] Jenkins, H. Fandom, negotiation, and participatory culture, in: P. Booth (Eds.), A companion to media fandom and fan studies, John Wiley \& Sons, Inc., Oxford, 2018, pp. 11-26. DOI: https://doi.org/10.1002/9781119237211n-themulti-million-dollar-fan-economy/

[8] Brown, S. Scott Brown on Sherlock Holmes, obsessed nerds, and fan fiction. Wired Magazine. 2009. Available at: https://www.wired.com/2009/04/pl-brown-6/

[9] Merriam-webster. Fandom. Definition of Fandom. 2021. Available at: https://www.merriamwebster.com/dictionary/fandom\#h1/.

[10] Sandvoss, C. Fans: The mirror of consumption. Cambridge, UK: Polity, 2005. pp.8. ISBN: 978-0745-62973-5.

[11] Coppa, F. A brief history of media fandom. Fan fiction and fan communities in the age of the Internet. Jefferson, North Carolina: McFarland \& Company, 2006. pp.41-59. ISBN 978-0-78642640-9.

[12] Bennett J. H. A Preliminary History of American Anime Fandom. University of Texas at Arlington, 2010. Available

at: https://www.academia.edu/download/37138974/A_ Preliminary_History_of_American_Anime_Fando m.pdf/

[13] Cook, M. L. Mystery Fanfare: A Composite Annotated Index to Mystery and Related Fanzines, 1963-1981. Popular Press, 1983. pp.5-24. ISBN: 087972-230-4

[14] Tobin, S. Fans and Videogames: Histories, Fandom, Archives. American Journal of Play. American Journal of Play, 2018. pp.237-239. ISSN: 1938-0399.

[15] Miller, G. Inside 'Serenity'. HowStuffWorks, 2011. Available at: https://entertainment.howstuffworks.com/serenity.h $\mathrm{tm} /$

[16] Irwansyah, I. and Lestari, A. F. Participatory Fandom of Army BTS Indonesia in the Digital Comic on Webtoon Apps. Journal Communication Spectrum: Capturing New Perspectives in Communication. 2020. pp.46-57. DOI: 10.36782/jcs.v9i1.1872.
[17] Kligler-Vilenchik, N. "“Decreasing World Suck": Harnessing Popular Culture for Fan Activism." In By Any Media Necessary. New York, USA: New York University Press, 2020. pp.102-148. DOI: $10.18574 / 9781479829712-004$.

[18] Public Intelligence. "National Gang Intelligence Center Juggalos Intelligence Report", 2011. Available at: https://info.publicintelligence.net/NGICJuggalos.pdf/

[19] Williams, J. P. and Ho, S. X. X. "Sasaengpaen" or K-pop Fan? Singapore Youths, Authentic Identities, and Asian Media Fandom. Deviant behavior, 2016. pp.81-94. DOI: 10.1080/01639625.2014.983011.

[20] Beller, J. Paying attention. Cabinet Magazine, 2006.

[21] Bueno, C. C. Attention economy: labour, time and power in cognitive capitalism. Rowman \& Littlefield International. New York London, 2016. ISBN: 1783488239

[22] Jhally, S. \& Livant, B. 'Watching as Working: the Valorization of Audience Consciousness'. Journal of Communication, 1986. pp.124-143, doi: 10.1111/j.1460-2466.1986.tb01442.x

[23] Nixon, B., 'The Exploitation of Audience Labour: A Missing Perspective on Communication and Capital in the Digital Era'. Reconsidering Value and Labour in the Digital Age, 2015. pp. 99-114, Palgrave Macmillan UK, London, doi: 10.1057/9781137478573_6 